\title{
The Internationalization Development Strategy of Yunnan Open University for ASEAN Higher Education
}

\author{
Huayi Wu \\ Yunnan Open University, 18687840086, Kunming, Yunnan Province, Xuefu Road 113, China, \\ wuhuayihappy@163.com,0871-5134058
}

Keywords: support services and education, science communication

\begin{abstract}
The internationalization of education is the inevitable trend of development of the Open University, emphasized the expansion of space and relevant international organizations, universities and institutions, multi-level and wide-ranging exchanges and cooperation. In this paper, by analyzing Yunnan Open University for ASEAN internationalization of higher education development of major opportunity and feasibility, proposes Yunnan Open University for ASEAN internationalization of higher education development strategy: On the basis of "seeking consensus and pursuing win-win", expands the exchanges and cooperation between relevant international organizations, universities and institutions, introduce high-quality educational resources, innovates Training Mode of Yunnan open University internationalization; On the basis of "connotation for the first and focusing on the development", relies on the Yunnan border ports, creates international Education Park and secondary colleges of Yunnan Open University internationalization, achieves its own characteristics and international matching; On the base of "building platform and sustainable development", forms rules and regulations of international development in Yunnan open University, realizes the comprehensive internationalization of teaching resources, research, social services.
\end{abstract}

\section{The major opportunity of Yunnan Open University international development for the ASEAN higher education}

Yunnan due to its unique geographical features and long-term benign political economic and trade cooperation operational mechanisms with the ASEAN countries, to promote and implement the internationalization of Yunnan Open University and ASEAN higher education provides a unique geographical and traditional exchanges and cooperation advantages, coupled with the strategic decisions of "a new round of western development of country ", " the national 12th Five-Year Plan ", " the main functional area planning of our country ","China facing the opening of Southwest bridgehead construction" and" nation-building Open University in China, " are more for the internationalization of Yunnan Open University and ASEAN higher education with an unprecedented opportunity for development.

\subsection{Unique geographical advantage of Yunnan}

Yunnan is window and door of China's gateway to Southeast Asia and South Asia, the south-west border with Myanmar, south of adjacent to Laos and Vietnam, border length of $4060 \mathrm{~km}$, of which China-Burma border $1997 \mathrm{~km}$, China-Laos border $710 \mathrm{~km}$, China -Vietnam border $1353 \mathrm{~km}$. There are 8 border prefectures of 26 border counties, and 3 neighboring countries of 6 provinces (states) 32 (city, town) bordering the town, 11 counties (cities) with neighboring cities and towns across the river (sector). The province has 13 first-class port, where the overland port 9 , aviation port 2(all to allow foreign aircraft import), water transport port 2; Inventory Control Point 7, which border with Myanmar 6, with Vietnam 1; Border trade Channel 90; Border trade point 103.

With the development of the China - ASEAN Free Trade Area, Yunnan has the initial formation of the three convenient access to Southeast Asia and South Asian countries: First, West Road, the channel along the Yunnan- Burma (Wan Kun) roads, China-India roads and Kunming to Dali railway westward, there are multiple ports and exit, respectively, arrived in Myanmar Myitkyina, 
Bhamo, Lashio and direct Yangon, but also Myitkyina to India Ray, with the Indian railway network is connected to the Bangladesh Dhaka, Hong Kong; Second, Middle Road channel, constituted by Lancang - Mekong River shipping, Kunming to Daluo road and XiShuangBanNa Airport to Laos, Myanmar, Thailand and extends to the channel in Malaysia and Singapore; Three, East Road, the channel to Yunnan - Vietnam Railway, Kunming - Hanoi Highway and with the development of Hong he River waterway airport, leading to Hanoi, Haiphong, and parts of the south.

Yunnan's unique geographical location and facilities and traffic conditions to further complete the Yunnan Open University for ASEAN higher education internationalization provide be richly endowed by nature conditions.

\subsection{Benign political economic and trade cooperation operating mechanism}

Yunnan and ASEAN countries have good political and economic cooperation and trade relations. Cooperation in politics: In recent years, the friendly and cooperative relations between China and ASEAN countries has developed rapidly, both sides increasingly close political relations, the national high-level visits frequently and at all levels, wide dialogue and cooperation in various fields, such as China and Thailand, Laos, Singapore and other countries signed a memorandum of cooperation education exchanges. Cooperation in economic and trade: First, Yunnan and Thailand, Laos, Vietnam, Myanmar and other ASEAN countries have maintained sound economic and trade relations, in 2011 the province's foreign trade import and export amounted to \$ 16.053 billion, an increase of 19.6 percent over the previous year. To ASEAN import and export of \$ 5.95 billion, an increase of 30.2\%, ASEAN has become the largest trading market in Yunnan Province; Second, Yunnan of China and ASEAN countries cooperation is advanced ahead ceaselessly. Greater Mekong Sub-region (GMS), Burma-China- India- Bangladesh (BCIM) and other multilateral, bilateral cooperation mechanisms, continue to promote with the cooperation in Yunnan and ASEAN countries of the deepening of; Third, Yunnan and ASEAN countries both sides of economic exchange platform improvements continuously, Kunming Trade Fair, South Asia countries Commodities Exhibition, China- South Asia Business Forum, and so on do better and better.

Yunnan and ASEAN's political economic and trade cooperation has laid a solid foundation for the internationalization of higher education Open University of Yunnan and ASEAN countries, 5-7 June 2012, Yunnan Open University successfully hosted the China-South Asia Forum On Education is the international development of a good start.

\subsection{The major opportunities of the national strategic decision-making for international}

In July 2009, Yunnan into a bridgehead for the Southwest open strategy proposed; on July 7, 2010, a new round of county western development strategy was fully implemented; on December 21, 2010, National Plan of the main functional areas (2010-2020) released; on July 29, 2010, the national medium and long-term education reform and development Plan (2010 2020) released; on October 24, 2010, the State Council issued the approval of Yunnan Province to carry out the national education system reform, and explore the construction mode of the Open University; on March 17, 2011, the 12th Five-Year Plan for national economic and social development of the People's Republic of China released; these are the international development of the Open University of Yunnan policy support, but also to the international development of Yunnan Open University has brought unprecedented opportunities.

\section{The feasibility analysis of Yunnan Open University international development for the ASEAN higher education}

\subsection{Yunnan Open University educational advantage}

Yunnan Open University in Yunnan Province as the only one of the earliest in modern distance and open education of provincial undergraduate colleges and universities now have the conditions and basis for the ASEAN internationalization of higher education. University now covers an area of 
916 acres, the total construction area of 270,000 square meters, and the teaching equipment worth 100 million Yuan; there are 681 teachers, associate professor accounted for 34\% of the full-time teachers, Received a graduate degree teachers accounted for $63.58 \%$ of the full-time teachers, University also engaged Yibin Wang, Zhiren Liang and so on well-known scholars as a consultant; there are all kinds of enrolled students in more than 80,000 students, of which more than 50,000 students in open education people, more than 6500 higher vocational education students, more than 7,000 adult education students in vocational education students, more than 2,800 people in secondary vocational education, more than 6000 students in continuing education and training for students nearly 2000 people, cadres more than 15,000 online students; for Yunnan and neighboring provinces to train 265000 college graduates; carried out two million people in all types of job training; Yunnan Open University as a leader has been formed, 36 City and industry campuses and 128 county-level workstation (teaching point) as a base to cover the province's urban and rural school systems.

It can be seen, Yunnan Open University has a superior educational advantages, Yunnan Open University for the ASEAN higher education sufficient to support the international development process.

\subsection{Yunnan Open University in collaboration with ASEAN higher education are highly complementary, a great development}

From the development situation of ASEAN countries, there is a big difference between the development of higher education, In 2008, Yongjun Feng according to a number of indicators of the gross domestic product (GDP), per capita gross national product (GNP), gross enrollment rate of higher education and other indexes, the ASEAN higher Education is divided into three levels: the first level is the higher education developed countries - Singapore, Thailand, The National University of Singapore, Nanyang Technological University and Chulalongkorn University in Thailand, Su Ketai.Exploration MATI LARP Open University have very perfect higher education system; the second level is the higher education moderately developed countries - the Philippines, Indonesia, Malaysia, University of the Philippines, Jakarta University in Indonesia, University of Malaya have a relatively perfect system of higher education; The third level is the higher education in less developed countries - Vietnam, Cambodia, Brunei, Myanmar, the national higher education is lagging behind, the shortage of educational resources, the obvious contradiction between supply and demand, there is an urgent need to introduce China's education resources to promote their own development of higher education.

\subsection{First revelation of the first test}

In the pilot construction of the Yunnan Open University, the University is committed to strengthen cooperation with the community, and the province's 16 city set up local support alliance, and Yunnan University and other 25 University set up the University Union support, and the China Tourism Association and other 14 industry set up industry support Union, and the China Unicom and other 19 enterprises set up the Enterprise Support Alliance, the establishment of four support alliance greatly enhance University capacity and service level of the Yunnan Open University.

At the same time, the University has established a good cooperative relationship of Thailand, the United States, Australia, Canada and other countries: in the early 1990s, Yunnan Open University and Thailand signed an agreement to keep the exchange of teachers and students; in 2006, Yunnan Open University successfully held the 20th Annual Meeting of the Asian Association of Open Universities (AAOU); in 2007, Yunnan Open University and U.S. Denver metropolitan State College carried out cooperation in teacher exchanges and student visits; in 2010, Yunnan Open University and Chisholm Institute of Australia joint schools, opened International Hotel Management, International Tourism Management, Western food and beverage management, mechanical and electrical integration of four professional and has started enrollment; signed a cooperation agreement with the Canadian Maple International Education Investment Group; recruited the first Lao public school students; in 2012, Yunnan Open University successfully held China - South Asia Education Forum. 
Four support coalition-building and foreign exchange on a pilot experience both for Yunnan Open University international development facing the ASEAN higher education laid a good foundation.

\section{The Internationalization Development Strategy of Yunnan Open University for ASEAN Higher Education}

One Strategy, on the basis of "seeking consensus, the pursuit of win-win ", expands the exchanges and cooperation between relevant international organizations, universities and institutions introduce high-quality educational resources, innovates Training Mode of Yunnan Open University internationalization.

Yunnan Open University-oriented ASEAN internationalization of higher education is the coordination of the "input" and "output". On the third level of countries - Vietnam, Cambodia, Brunei, Myanmar, we focus on the main "output", and actively expand its higher education market, providing quality educational resources, various forms of training and seminars by learning the results of certification and credit transfer form to attract the students of these countries to the Yunnan Open University of education. On the first level, second level of countries - Singapore, Thailand, Laos and so on, we focus on the "input" , "input" and "output" each other to take the length of way, strengthens exchanges and cooperation between educational organizations, universities and research institutions, through close exchanges and cooperation, we can fully experience and look at the ASEAN higher education teaching and management experience, positive thinking Yunnan Open University personnel selection criteria and training model, and on the basis of "seeking consensus pursuit of win-win ", gradually explore the long-term mechanism of Yunnan Open University of the internationalization of innovative training model.

Two strategies, On the basis of "connotation for the first and focusing on the development", relies on the Yunnan border ports, creates international Education Park and secondary colleges of Yunnan Open University internationalization, achieves its own characteristics and international matching.

Yunnan has formed the more concentrated foreign channel and port groups - the West, Central, East Road, there are a kind of port 13,two kinds of port 7,border trade channel 90,border trade point 103, with "even the four provinces, adjacent three countries, nearly eleven country " a unique regional characteristics, is an important window for international development in Southeast Asia, however, Yunnan province border show the embarrassing situation of higher education is extremely lacking, seriously affect the process of international development. In view of this, Yunnan Open University should take this opportunity to create International Education Park and secondary College of the international development, by establishing international credits for Chinese and foreign students, which will realize mutual recognition and credit transfer, but also allow students to experience different cultures and international communication, ultimately fill the blank of the extreme shortage of Higher Education in border crossings and Yunnan Open University in their own characteristics with international docking.

\section{References}

[1] Shaogang Zhang, Yongfeng Wang.International strategy and policy options of the Open University in China [J]. Modern Distance Education, 2011(5).

[2] Yunnan Commerce Department. Port Overview[EB/OL].Http://www.bofom.gov.cn/, 2012-5-27.

[3] Jia Ren.Facing the economic development of Yunnan "12th Five-Year" period, Opportunities, Challenges and Strategies [J]. Social Sciences, 2011(6).

[4] Chongmin Luo.Building an open universities, government what to do[C]. Selected papers from Yunnan Open University Pilot Project, 2012(4). 